Revista de Comunicación y Salud, 2017, Vol. 7, pp. 49-60

Editado por Cátedra de Comunicación y Salud

ISSN: 2174-5323 (impreso) 2173-1675 (electrónico)

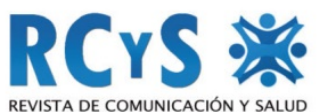

Enviado 28 de noviembre de 2016

Aprobado 7 de febrero 2017

\title{
ANÁLISIS DE LOS PROCESOS PSICOLÓGICOS DE PERCEPCIÓN Y MEMORIA EN EFECTIVIDAD DE LOS JINGLES PUBLICITARIOS ${ }^{1}$
}

\section{Analysis of the psychological processes of perception and memory in the effectiveness of advertising jingles}

\author{
Néstor Raúl Porras Velásquez ${ }^{2}$ \\ Fundación Universitaria los Libertadores. Colombia
}

\section{Resumen}

El objetivo de este artículo es analizar los procesos psicosociales de la percepción y la memoria en la efectividad de los jingles publicitarios. La metodología empleada fue la revisión documental. Los resultados muestran que históricamente la publicidad comercial ha apelado a la persuasión emocional para afectar positivamente la percepción y memoria de los anuncios. La música es un factor clave en la apelación a lo emocional con ritmos pegajosos y melodías que anuncian e identifican una marca o producto. Las conclusiones evidencian que la efectividad del anuncio está en la recordación del mensaje y en el incremento de las ventas. Con la estrategia de acompañar los mensajes con música lo se busca es que el público consuma mas. Palabras clave: Análisis psicosocial, percepción, memoria y jingles publicitarios.

\begin{abstract}
The objective of this article is to analyze the psychosocial processes of perception and memory in the effectiveness of advertising jingles. The methodology used was the documentary review. The results show that commercial advertising has historically appealed to emotional persuasion to positively affect the perception and memory of ads. Music is a key factor in appealing to the emotional with sticky rhythms and melodies that announce and identify a brand or product. The conclusions show that the effectiveness of the announcement is in the recall of the message and in the increase of sales. The strategy of accompanying messages with music is sought is that the public consumes more.
\end{abstract}

Key words: Psychosocial analysis, perception, memory and advertising jingles.

\footnotetext{
1 Artículo producto del proyecto de investigación sobre el Análisis y efectos de los Jingles publicitarios en Colombia. Este proyecto se realizo en colaboración con la facultad de comunicación social de la Fundación Universitaria Los Libertadores.

${ }^{2}$ Autor de contacto: Nestor Raúl Porras nrporrasv@libertadores.edu.co
} 
Análisis de los procesos psicológicos de percepción y memoria en efectividad de los jingles publicitarios

\section{Como citar el artículo}

Porras Velásquez, N. R. (2017). Análisis de los procesos psicológicos de percepción y memoria en efectividad de los jingles publicitarios. Revista de Comunicación y Salud, vol. 7.49 - $\quad$ Recuperado htp http://revistadecomunicacionysalud.org/index.php/rcys/article/view/120

\section{INTRODUCCIÓN}

\section{"Sin música la vida sería un error" Nietzsche}

Es evidente que la vida humana sin música seria muy difícil de soportar. Sin embargo, este documento se propone entre otras coas, indagar sobre el uso y los efectos de la música en los anuncios publicitarios. Para esto es necesario indagar inicialmente sobre los procesos psicológicos básicos de percepción y memoria, que han sido ampliamente estudiados desde la perspectiva conductual de la psicología, a través de la asociación de estímulos.

De esta manera, desde sus inicios, a comienzos del siglo $X X$, la psicología de corte experimental en los Estados Unidos de Norteamérica estuvo interesada en aplicar sus conocimientos y metodología científico al campo de la publicidad, Walter Dill Scott, en 1901 y 1903 publica sus primeros artículos sobre dicha temática. Para la mayoría de autores Scott es considerado el padre y pionero de la psicología de la publicidad, en el país del norte.

Desde hace mucho tiempo sabemos que la música es una compañera íntima de nuestras emociones. La música que escuchamos dice más sobre nosotros mismos que la forma de vestir y crea potentes lazos afectivos y sociales entre las personas. Por esta razón, no es extraño que la música sea un ingrediente esencial para la publicidad. Pero, ¿cómo se compagina la música con la publicidad? Básicamente, a partir de la asociación de estímulos; donde los procesos psicológicos de percepción y memoria determinan en gran medida el comportamiento del consumidor.

Veamos inicialmente algo de la historia de la publicidad que nos sirva de marco referencial para esta investigación.

\section{HISTORIA DE LA PUBLICIDAD}

La publicidad tal y como la conocemos hoy siempre ha estado ligada a la comunicación masiva. Desde la revolución industrial, el surgimiento de empresas y la producción masiva. La publicidad busco informar a los consumidores sobre nuevos productos y servicios. Además de servir de medio para comunicar las ventajas de ciertas marcas y productos.

Para Victoroff (1980), la publicidad es "un sistema de comunicación, que pone en relación a productores y consumidores a través de los medios de comunicación de masas" (p.10). Sostiene que la publicidad es una "industria cultural", que distribuye una cultura de masas. Además, la publicidad es un "arma" del marketing al servicio de las estrategias comerciales de la empresa. La publicidad también pude ser entendida como una forma capitalista de propaganda y de explotación de los consumidores. Etc. 
Análisis de los procesos psicológicos de percepción y memoria en efectividad de los jingles publicitarios

Tal complejidad de definiciones depende sin duda de la complejidad del fenómeno publicitario, suspendido simultáneamente a la economía, al derecho, la cultura, al lenguaje, al audiovisual, etc., según la perspectiva que se adopte y la prioridad que se dé a uno de sus aspectos.

Hacer publicidad comercial ¿no implica, o supone hacer pública una oferta de venta? Es a la vez un medio de difusión y una técnica de persuasión. Destinada a dar a conocer al público la existencia de un producto a de un servicio, también pretende suscitar o incrementar el deseo de adquirir este producto o de recurrir a este servicio. (p. 11).

\section{La incitación a la compra}

Recordemos, además, que la publicidad ejerce su acción en el seno de un conjunto otras técnicas comerciales que globalmente constituyen lo que designamos como marketing. Todas estas técnicas persiguen el mismo objetivo: favorecer la venta. Por eso, no siempre es fácil trazar con precisión las fronteras que delimitan la publicidad en el seno de este conjunto. Lo que sí es claro, es la incitación a la compra por parte la comunicación publicaría.

Se reserva el uso de la palabra publicidad únicamente para los mensajes difundidos por los grandes medios: prensa, televisión, carteles, radio, cine, etc.

Es habitual limitar el término publicidad a solo aquellos mensajes que hagan mención explícita del producto, la prestación de un servicio o necesariamente promover la venta. En pocas palabras, la publicidad sigue evolucionando y ya no solo nos comunica emociones sino que busca la empatía compartidas con el producto, o con la marca, estableciendo una relación y compartiendo experiencias (Martín-Raquero \& Alvarado-López, 2007).

De acuerdo con Puig (1986), la publicidad es un medio de comunicación vigoroso e inmerso en los últimos adelantos tecnológicos, y una de las fuerzas económicas que mueve al mundo. Para algunas personas la publicidad es venta. Venta de un producto o servicio, nada más ni nada menos. En ese sentido, la publicidad es un medio de venta, es decir, la publicidad es un medio de acción psicológica, ya que motiva o impulsa a la compra. Sin embargo, para Martín-Raquero \& Alvarado-López (2007), definir la publicidad como un instrumento de venta es retrotraerla a épocas pretéritas.

Es indiscutible que la publicidad sigue siendo una profesión dinámica que cambia constantemente. Dicha evolución nos lleva hablar de una "nueva publicidad" más personal e interactiva que la de antes.

De acuerdo con Wells, Moriarty \& Burnett (2007), la publicidad funciona en el nivel más básico

"si las personas le prestan atención, están conscientes de la marca y recuerdan tanto la merca como la publicidad. Eso es impacto a nivel perceptivo. Pero un anuncio también puede estar diseñado otros cinco tipos de respuesta general: puede proporcional información útil, tocar emociones, darle personalidad a una marca, cambiar las actitudes del consumidor y hacer que las personas actúen" (p. XXII).

Por esta razón, es oportuno y adecuado proponer un sistema integrado de comunicación en el marketing empresarial de hoy, que haga más consistente y efectivo la labor de la publicidad. 
Análisis de los procesos psicológicos de percepción y memoria en efectividad de los jingles publicitarios

De acuerdo con Martín-Raquero \& Alvarado-López (2007), la sociedad de mercados y mercantilizada, se basa en la insatisfacción permanente del consumidor, sobre la sensación de una carencia, que es más espiritual que material, pero que la publicada promete compensar a través de las mercancías. Por esta razón, cuanto más pobres y más insatisfechos, mejor para el marketing. Ahora bien, como la compra de una mercancía nos volverá todavía más pobres, la insatisfacción no puede sino aumentar con el consumo. Aspecto también resaltado por Bauman. En pocas palabras,

"para conseguir sus propósitos, la publicidad lo primero que debe conseguir es la insatisfacción del consumidor; es necesario que te sientas demasiado feo, demasiado gordo, demasiado pobre, que pienses que la gente de tu entorno no te quiere lo suficiente" (p. 26).

En este contexto, si reconocemos que la publicidad es un discurso eminentemente burgués, se sostiene en la idea de que se pueden comprar valores, virtudes, estima, con dinero; no resulta extraño plantear que: "la publicidad se convierte en una ideología y en una religión; las mercancías ya no son objetos, son símbolos, rodeados de una mitología: no son fabricados, son creados" (Martín \& Alvarado, 2007, p. 26). Es evidente, en este planteamiento que para que el mecanismo funcione es obvio que hace falta una disposición de la mente humana por lo que se tiende a confundir lo representado y el representante.

Respecto al funcionamiento de la publicidad contemporánea como conjunto de técnicas que se sitúan en el corazón mismo de la cultura humana y que reflejan el lado más intimo del ser humano de nuestra época: la economía del esfuerzo, la gratificante inmediatez de la mirada, el empleo de la metáfora con el fin de hacer conocido lo desconocido, las personificaciones que "humanizan" los objetos, la confusión entre el signo y lo representado, el poder de los símbolos, y sobre todo la tendencia del hombre actual de volverse primitivo, mas emocionales. En aceptar que: "lo que rechaza la razón con plena lucidez tal vez lo acepten nuestras emociones" (Gombrich, 1994, p. 280).

Finalmente, no podemos olvidar que: según López (2007), la publicidad es, además de una actividad profesional ligada al consumo, una propuesta lúdica inspiradora, que está ligada al imaginario mágico del ser humano, con el fin de que el publico despierte sus fantasías a través de las propuestas comerciales. En este sentido, habría que preguntarse también ¿qué fantasía no tiene un final feliz? En otras palabras, la publicidad no puede ser tomada como un reflejo de la realidad tal cual es, sino de la realidad tal como nos parece que debería ser.

De otro lado, la psicología económica tiene una importancia decisiva en la investigación de mercados. La toma de decisiones de los consumidores, las reglas de decisión, las actitudes, las intenciones, las conductas y la satisfacción están entre los conceptos utilizados por la investigación de mercados, los análisis de las organizaciones de consumidores y la administración. La psicología económica se convierte, de este modo, en un campo de aplicación fértil y estimulante para la psicología social y cognitiva. $Y$ viceversa: psicólogos cognitivos y sociales pueden también aprender de los psicólogos economistas.

Para Raau (2005):

"La psicología económica no es solamente relevante en el contexto microeconómico de la investigación de mercados, sino también en el contexto 
Análisis de los procesos psicológicos de percepción y memoria en efectividad de los jingles publicitarios

macroeconómico de la política sobre la inflación, desempleo, pobreza y riqueza, consumo y medio ambiente. (Fred Van Raau, 2005)

En el mismo sentido, Simón (1973), plantea que

"lo artificial se diseña según funciones, objetivos y adaptaciones imperativas y prescriptivas. Las ciencias artificiales, y la economía junto con la psicología los son, no pretenden simplemente la explicación de las cosas, sino diseñar como deberían ser las cosas artificiales para la consecución de unos fines" (p.16).

En consecuencia, el hombre económico puede ser una realidad artificial diseñada en función de ciertos intereses y motivaciones.

\section{PSICOLOGÍA Y PUBLICIDAD}

Desde sus inicios la psicología científica busco aplicar sus conocimientos a situaciones cotidianas. En ese sentido, la psicología de la publicidad va más allá de la imposición de marcas comerciales para su posterior consumo. En su particular visión, los investigadores aseguran que la psicología de la publicidad no es un área de la psicología del consumidor, como se ha abordado hasta ahora, sino un campo independiente que comparte algunos asuntos con la psicología del consumidor.

Aunque, tradicionalmente, la intersección entre la psicología del consumidor y la psicología de la publicidad se basa en una teoría que explica la 'huella mental' que deja la publicidad en cada individuo.

La publicidad se ha concentrado principalmente en las relaciones que tiene la marca tanto con el producto como con sus atributos, y ha olvidado que es en la experiencia de consumo donde el cliente comprueba si los atributos prometidos son ciertos.

Para la psicología asociacionista, la exposición continuada o repetida de la publicidad contribuye a que los elementos anteriormente mencionados vayan creando la huella mental. En términos psicológicos, se trata de un proceso de 'aprendizaje asociativo' mediante el cual el cerebro permite relacionar los eventos que la persona percibe del mundo, gracias a su cercanía espacial o temporal.

Es decir que la publicidad funciona gracias a la gran capacidad humana de asociar los estímulos del ambiente que nos rodea. En ese sentido, los anuncios comerciales son una especie de 'escuela' en la cual las personas se convierten en 'aprendices' sobre la existencia de unos productos con una marca determinada y con unas características particulares.

En síntesis, la exposición continuada o repetida de la publicidad contribuye a que los elementos anteriormente mencionados vayan creando la huella mental. En términos psicológicos, se trata de un proceso de 'aprendizaje asociativo' mediante el cual el cerebro permite relacionar los eventos que la persona percibe del mundo, gracias a su cercanía espacial o temporal.

\subsection{Procesos psicológicos básicos de percepción y memoria}

El procesamiento de la información por parte de las personas ha sido ampliamente estudiado por los psicólogos de orientación cognitiva. Desde esta 
Análisis de los procesos psicológicos de percepción y memoria en efectividad de los jingles publicitarios

perspectiva, es importante entender el proceso que realiza cada sujeto para recordar los eventos significativos para él.

De acuerdo con la teoría que se conoce como "conexionista- simbólica" en Ciencias del Comportamiento, el producto cognoscitivo de la exposición sistemática a los estímulos publicitarios es una red de conceptos, una especie de mapa complejo de relaciones mentales entre múltiples marcas, productos y atributos. En pocas palabras, es importante resaltar que cada persona, de acuerdo con sus experiencias, construirá la red de forma distinta. Por más masiva que sea la publicidad, el procesamiento psicológico de la misma será siempre individual.

Para Martín \& Alvarado (2007), el triunfo de los sentidos en las estrategias comerciales obedece, entre otras cosas a: "la importancia de las sensaciones ya ha sido explicada desde distintos ámbitos del saber, especialmente desde la psicología, y no cabe duda que del desarrollo sensorial va a depender todo lo que el ser humano sabe, piensa, siente y expresa" (p.120). Para estos autores, son muchos los datos que demuestran la importancia de la estimulación sensorial y de las dos formas de interactuar con el ambiente, desde la actividad, o más bien desde una pasividad, esperando que productos de consumo nos estimulen y nos hagan sentir.

Es claro que los ciudadanos actuales, o no tienen tiempo o no saben qué hacer con él. El aburrimiento, es un problema importante para el mercadeo, ya que en cualquier situación sirve para provocar deseos, de tener más tiempo para hacer más cosas, o para no hacer nada. La publicidad busca darle sentido al tiempo perdido o ganado. Donde los deseos pueden ser satisfechos a través de bienes de consumo. En síntesis, la publicada provee la alegría de satisfacer los deseos y proporcionar buenos motivos para consumir.

De otro lado, encontrar placer inmediato. "porque tu lo vales', "te mereces un descanso", "porque negarse uno mismo"... aumentar el deseo adquisitivo para poder disfrutar de la prosperidad y el hedonismo. Donde se estimula principalmente la percepción visual y sobretodo la percepción auditiva. La estrategia consiste en despertar los sonidos se convierte en una tarea de los creativos publicitarios y es el objetivo principal de números productos de consumo: jabones, lociones, aceites, aromáticos... es la era del triunfo de los sentidos y está tendencia se utiliza para publicitar hoteles, restaurantes, y otros servicios que hablan de la armonía de sus elementos, de la emoción de la música, del color de los decorados; en definitiva de ambientes sinérgicos donde el cuerpo y la mente alcanzan el bienestar y la perfecta armonía.

En ultimo termino, la búsqueda de la identidad, de las raíces, de los grandes ideales que den sentido a la vida se convierten en una autentica necesidad, que será recogida por las estrategias del marketing para presentar productos de consumo que recuperen el gusto por "lo rural", lo "ecológico", lo hecho a mano", "lo autentico, "lo recalcado"...

\section{MÚSICA Y PUBLICIDAD}

Desde hace mucho tiempo sabemos que la música es una compañera íntima de nuestras emociones. La música que escuchamos dice más sobre nosotros mismos que la forma de vestir y crea potentes lazos afectivos y sociales entre las personas. Por esta razón, no es extraño que la música sea un ingrediente esencial para la publicidad. Pero, ¿cómo se compagina la música con la publicidad? El experto italiano en comunicación Tomas Bacoccoli ofrece en la revista especializada en 
Análisis de los procesos psicológicos de percepción y memoria en efectividad de los jingles publicitarios

marketing y publicidad Horizont algunas claves para fusionar los anuncios publicitarios con la música:

1. El sonido asociado a una marca es tan importante como su imagen.

2. Para decidir la música de la que quieren colgarse del brazo, las marcas deben tener los oídos muy abiertos y escuchar los gustos musicales de su público objetivo.

3. La cooperación entre marcas y músicos debe ser creíble de cara al espectador. De lo contrario, al consumidor la música le sonará "desafinada".

4. Las marcas deben asegurarse de que la música cumple un objetivo y que funciona en todas las plataformas. Hay que tener en cuenta que la música mediocre tiene potencial suficiente para dañar a las marcas.

5. La música es algo más que entretenimiento puro y duro. Es un medio y como tal debe estar sujeto a métricas.

6. Si la música tiene un próspero futuro por delante, también lo tiene inevitablemente la publicidad radiofónica.

De oro lado, es evidente que la elección de la música en una campaña publicitaria no es una decisión fácil de asumir. Pues, si bien existen innumerables campañas que han conseguido tener mucha notoriedad y un gran éxito de ventas prescindiendo de ella, la música puede ser una herramienta fundamental y decisiva para su éxito.

Al hacer una breve historia de las canciones publicitarias, encontramos que las canciones han existido en la publicidad desde principios de 1920. Note Line Music Productions atribuye la primera canción comercial moderna a una publicidad de cereal de desayuno del general Mills de 1926 con un cuarteto a capella. Las canciones de anuncios se hicieron más prominentes en la década de 1930 y más tarde se convirtieron en un elemento importante en la publicidad televisiva. El desarrollo de la tecnología a través del tiempo se ha sumado a las capacidades musicales de las canciones y la mayoría de las canciones publicitarias del siglo XXI se grabó en estudios profesionales de música.

La intención de unir música y publicidad es básicamente lograr que el consumidor recuerda la marca que se está publicitando. De esta manera, se pretende, entre otras cosas, crear conciencia de la marca y promover su recordatorio se encuentran entre los principales objetivos de los anunciantes. Darle al mercado una familiaridad con su marca es necesario para de poder impulsar la comprar sus productos. El uso de canciones pegadizas y temas memorables son dos convenios de promoción para recordar una marca en publicidad. La estrategia de incorporar una canción pegadiza en sus campañas publicitarias puede tener un impacto duradero para la marca. La gente, a menudo, se encuentra cantando canciones de anuncios sin pensar.

Desde el punto de vista psicológico, añadir un elemento musical a un mensaje publicitario aumenta significativamente la recordación del mensaje, señala Note Line Music Productions. Las canciones tienen una forma especial de conectarse con los receptores emocionales de los consumidores. Cuando la gente en el mercado de destino de la marca se encuentra cantando la melodía asociada a un momento de alegría, paz y bienestar, por ejemplo, conectan ese sentimiento directamente con la marca. En última instancia, la música, apunta hacia los residuos cognitivos de la percepción y la memoria.

Si observamos con atención, los anuncios que aparecen en televisión, nos daremos cuenta que el $90 \%$ de estos utilizan algún tipo de música. En muchas 
Análisis de los procesos psicológicos de percepción y memoria en efectividad de los jingles publicitarios

ocasiones, esta tiene una función secundaria para amenizar los 20 ó 10 segundos que dura el anuncio, como algo secundario. Pero eso es un error; la música ha de cumplir una función específica según las necesidades del brief y la decisión del equipo creativo, pero nunca ha de dejarse en un segundo plano o ponerla sin ninguna intención concreta.

En este sentido, la música publicitaria se puede clasificar en diferentes tipos, cada una de ellas con sus ventajas e inconvenientes. Todo dependerá de la función que queramos que cumpla y el efecto que queramos causar en el espectador. Hay dos grandes grupos en los que se separa la música publicitaria: 1) Preexistente: creada con anterioridad por algún artista. 2) Original: creada especialmente para una campaña en concreto. Lo importante en este caso, es reconocer que cualquiera de ellas es igual de válida a la hora de hacer una campaña. Lo importante es hacer una elección coherente con los objetivos y con el mensaje que se quiere transmitir.

De acuerdo con Vives (2013), El poder del sonido para comunicar emociones es asombroso. No somos muy conscientes de ello pero nos afecta a distintos niveles, desde el psicológico y conductual, hasta el puramente fisiológico o cognitivo. El sonido emociona: nos conmueve y estimula; nos anima o nos entristece. También puede inquietarnos e incluso perturbarnos. La música es una sonoridad organizada; el arte de combinar sonidos agradables para el oído.

De otra parte, el marketing que saca partido de este potencial es el Audiobranding. Utiliza el sonido de forma estratégica. Su objetivo es trasladar la personalidad de la marca a todos los puntos de contacto. Las empresas proponen, aún sin saberlo, una experiencia sonora y con ella construyen relaciones emocionales con sus grupos de interés. Es una de las grandes oportunidades no explotadas del marketing emocional, según muchos 'el Santo Grial' del marketing.

Preocupadas por como son percibidas, las marcas destinan grandes energías a definir su identidad gráfica. Sin embargo, aunque parezca mentira, pocas son las que gestionan las relaciones sonoras con sus grupos de interés de una forma estratégica.

Con el fin de obtener una radiografía del binomio música/marca, la agencia sueca Heartbeats International publicó en 2009 el estudio 'Sounds like Branding'. Se enviaron cuestionarios a 70 top brands internacionales como Adidas, Audi, BMW, Disney, Ebay, McDonald's, Microsoft, Pepsi, Nokia, Sony o Siemens para conocer de primera mano su estrategia musical.

Los resultados señalan que el $97 \%$ de las empresas cree que la música puede fortalecer su marca. También que el $76 \%$ de ellas utiliza activamente música en sus estrategias de marketing, aunque sólo el $40 \%$ ha tratado de identificar como suena su marca y únicamente un $20 \%$ de ellas dispone de un logotipo sonoro. Otro dato relevante es que el $70 \%$ de las empresas gasta menos de un $5 \%$ de su presupuesto de marketing en música. Parece evidente que, aun identificando el poder de la música, las marcas no actúan en consecuencia.

Ate la pregunta: ¿Cuáles pueden ser las experiencias sonoras de una marca? La respuesta es, muchas. Cada día existen más: cuñas de radio, anuncios de televisión, relaciones telefónicas de la marca, eventos, ferias, aplicaciones móviles, podcasts, branded audio, páginas web... También podemos escuchar la marca en la experiencia sonora de los propios productos, el sonido de las instalaciones de las empresas o en la interacción con sus empleados. Para que una marca obtenga una entidad sonora efectiva, es importante que emprenda un proceso estratégico. Que tome la palabra de forma consistente y unificada. 
Análisis de los procesos psicológicos de percepción y memoria en efectividad de los jingles publicitarios

La clave del éxito de una marca, consiste en disponer de una identidad sonora adecuada. Ahora bien, para poder destilar su personalidad en términos musicales, hay que considerar la música como lo que es: un lenguaje. El rigor que empleamos en la definición de un territorio gráfico debe también estar presente cuando se genera el territorio musical de la marca.

La creación de una identidad sonora debe proceder pues, de un análisis profundo, una planificación estratégica pertinente, una investigación creativa audaz, un vínculo con la personalidad de la marca y un despliegue apropiado y bien contextualizado.

En síntesis, el éxito de una campaña publicitaria audiovisual consiste en saber elegir todo el conjunto de elementos de sonido e imagen que la forman y en que eso sostenga una coherencia, una relación entre la parte estética y comunicativa. En numerosas ocasiones, el sonido, concretamente la música, proporciona un valor añadido en la notoriedad de marca, aunque otras veces es una simple base o apoyo, vehículo de la historia o se encuentra en función de situar la acción en un determinado lugar o momento cronológico. En televisión, por ejemplo, la publicidad se oye más que se ve, de ahí la importancia de elementos sonoros que ayuden a recordar el anuncio, en aras de su eficacia comunicativa.

\section{JINGLES EN LA PUBLICIDAD}

Los jingles son canciones publicitarias, cuya letra y música están creadas específicamente para un anuncio o campaña. Es el mensaje publicitario hecho canción; la letra es el texto publicitario que incluye el nombre del producto, las características de este, la marca... Incluso en el jingle, a veces se añaden los beneficios que aporta el producto en cuestión, el precio y los valores de la marca. Cantando puede explicarse todo lo que se desee. Por eso, en la gran mayoría de casos, los creativos publicitarios son los responsables de crear la letra. Después se encargan de contratar a un músico que componga una melodía coherente y acorde con lo que se quiere decir y transmitir. El siguiente ejemplo de NSB para especias Dos Anclas es un claro ejemplo de esto.

\section{1 ¿Qué es un jingle?}

El Jingle es un mensaje publicitario cantado. Consiste en una canción de corta duración (de 5 a 60 segundos) y de fácil recordación que se utiliza para acompañar a los anuncios de publicidad. En los jingles se acostumbra decir el nombre de la marca a publicitar o el slogan creado para la campaña. A este tipo de estrategia se le conoce como branding auditivo.

\subsection{Tipos de Jingle}

Hay dos tipos de Jingles y se clasifican según su función:

1. Jingle Identificador: Ráfagas cortas de música que dividen las secciones de una emisora. Su labor es identificar a la emisora o a los programas que se transmiten por ella.

2. Jingle Publicitario: Su función es anunciar un producto o servicio. 
Análisis de los procesos psicológicos de percepción y memoria en efectividad de los jingles publicitarios

La importancia del Jingle se encuentra en quedarse impregnado en la mente del receptor del mensaje. Para lograr dicho objetivo el Jingle debe ser claro, corto y fácilmente identificable.

Las funciones principales de los Jingles, es ser inicialmente persuasivos, de fácil recordación, crear vínculos afectivos entre la marca y el consumidor.

En otras palabras, la música es un buen soporte para el texto. Si la letra y la música son buenas, la recepción del mensaje está asegurada. Es más fácil recordar un mensaje cuando es cantado que si te lo cuentan. Los jingles suelen repetir muchas veces la marca anunciante como parte de la letra de la canción y al receptor de mensaje esto parece no importarle, ya que no suele ser tan forzado como cuando se nombra a la marca sin música.

Crear lazos afectivos, significa que, si la canción es pegajosa, genera un buen clima, dando sensaciones positivas a quien la escucha. Por tanto ayudan a generar atracción por la marca. Con un jingle creativo y con un buen estudio de públicos objetivos, podremos lograr que la marca sea recordad de por vida.

Los jingles publicitarios aparecen por primera vez en la historia en Estados Unidos de Norteamérica, en la década de 1920 a la par de las emisiones radiales, siendo uno de los primeros y mejor logrados el que se titulaba "Have You Tried Wheaties?"

Como todas piezas publicitarias que se desarrollan para realizar un campaña, es muy importante que antes de crear un jingle se realice una estrategia publicitaria y si ella determina que el camino correcto para alcanzar los objetivos de venta es el jingle, recién podremos pensar en esta pieza para comunicar.

\section{EFECTIVIDAD DE LOS JINGLES PUBLICITARIOS}

La importancia de un buen jingle es transmitir un mensaje publicitario de una manera musical y entretenida. El jingle se aloja en la mente del espectador y, junto a él, el producto o la marca anunciada. Existen estudios que afirman el extraordinario poder de fijación de la música en la mente frente al de la palabra hablada.

Entre la década de los años 50 y 70 el jingle vivió su época dorada. Las marcas comenzaron a bombardear a la población con sus temas musicales, siempre acompañados de una simpática y pegadiza rima. En una época en la que la población se encontraba saturada de información, esta técnica publicitaria ayudaba a que los espectadores recordaran fácilmente el mensaje.

La pregunta es: ¿Por qué los jingles funcionan? La efectividad de la técnica del jingle reside en su musicalidad y la facilidad para ser recordado, además de poder repetir varias veces el nombre del producto o marca anunciada sin llegar a ser pesado. Esta técnica facilita la creación de lazos afectivos entre el espectador y la marca anunciante. Los anuncios cantados resultan menos repetitivos y pesados que el resto y, por lo tanto, son más persuasivos.

Es así como surgirá el "blink". Un spot ultra breve (En ocasiones no supera los 2 segundos de duración) que el espectador reconoce justo después de que éste haya terminado. En ocasiones contienen una fugaz melodía de 6 notas (como es el caso de la aseguradora Línea Directa), la cual permite la asociación directa con la marca.

\section{CONCLUSIONES}

Por el momento es pertinente señalar la influencia de los jingles en la percepción y recordación de las marcas y productos publicitados, tiene que ver directamente 
Análisis de los procesos psicológicos de percepción y memoria en efectividad de los jingles publicitarios

con lo que plantea Braudillard al señala que "la publicidad es un proceso mediador que se ha integrado en el sistema de los objetos y no solamente porque promueve su consumo sino porque, ella misma, como actividad semiótica se transforma en objeto de consumo" (Aprile, 2000, p.19).

En este sentido, la publicidad informa y aconseja, para facilitar la toma de decisiones. Orienta, dirige, persuada y advierte.

De hecho, la publicidad no solo anuncia bienes y productos comerciales: también promociona hábitos de consumo, estilos de vida y valores. Así, el consumo de bienes surge como un fenómeno que excede en mucho el aspecto económico. El público aprecia no tanto lo que los productos le ofrecen funcionalmente como lo que prometen emocionalmente o sugieren en un nivel simbólico. Considerada en este contexto, la publicidad es multifacética: combina la información con la persuasión y el espectáculo. (Aprile, 2000),

La publicidad es una realidad económica e industrial pero, también, un renovado y rico archivo de modos culturales. Asimismo, un espejo donde se reconoce la sociedad, pero, a su vez, un instrumento de influencia y poder.

A pesar de la probada eficacia retórica de los mensajes publicitarios para despertar necesidades y deseos latentes, poco se ha hacho para desarrollar el corpus teórico que le dé a la publicidad jerarquía académica. Los textos y manuales en uso se agotan en el cómo sin dar sólidas razones del por qué ocurre dicha situación. En pocas palabras, podemos afirmar que este momento de la historia de la humanidad, se puede afirmar categóricamente que somos lo que consumimos.

\section{REFERENCIAS BIBLIOGRÁFICAS}

Aprile, O. (2000). La publicidad estratégica. Buenos Aires: Paidos.

García Dauder, S., \& Thomas, H. (2011). Psicología aplicada a la publicidad. Madrid: Dykinson.

Gombrich, E. H. (1994). Imágenes simbólicas. Madrid: Alianza

La importancia de un buen jingle. (2016). Recuperado de http://publiweek.blogspot.com.co/2012/03/la-importancia-de-un-buenjingle 25.html

López, B. (2007). Publicidad emocional. Estrategias creativas. Madrid: ESIC.

Martín-Raquero, M., \& Alvarado-López, M. (2007). Nuevas tendencias en la publicidad del siglo XXI. Sevilla: CS Comunicación Social.

Puig, J. (1986). La publicidad: historia y técnicas. Barcelona: Mitre.

Publicidad y música en el neuromarketing. (2014). Recuperado de http://www.brandreportblog.com/musica-y-publicidad-marketing-para-los-oidos/

¿Qué es un jingle? (2015). Recuperado de creativo.blogspot.com.co/2013/08/el-jingle-publicitario.html

Seis (6) claves para convertir la publicidad en música para los oídos del consumidor. (2014).

Recuperado

de

http://www.marketingdirecto.com/actualidad/checklists/6-claves-para-convertirla-publicidad-en-musica-para-los-oidos-del-consumidorl

Victoroff, D. (1980). La publicidad y la imagen. Barcelona: Gili.

Vives Xiol, R. (2013). El poder de la música en el marketing. Recuperado de http://www.puromarketing.com/44/16154/audiobranding-poder-sonido-musicaaplicados-marketing.html 
Análisis de los procesos psicológicos de percepción y memoria en efectividad de los jingles publicitarios

Wells, W., Moriarty, S. \& Burnett, J. (2007). Publicidad: principios y práctica. México: Pearson. 